\title{
DEVELOPING KNOWLEDGE OF PROSPECTIVE PRIMARY TEACHERS ABOUT MATHEMATICS TEACHING BY THE USE OF A MULTIMEDIA CASE
}

\author{
Luís Menezes, Ana Maria Costa \\ Polytechnic of Viseu and CI\&DETS (PORTUGAL)
}

\begin{abstract}
This study aims to understand the potential of a multimedia case in mathematics education for developing prospective teachers' knowledge of inquiry-based mathematics teaching and instructional communication that supports it. The multimedia case called "Cube with stickers" was developed in the P3M project - Professional Practices of Mathematics Teachers, by Hélia Oliveira, Ana Paula Canavarro and Luís Menezes. The multimedia case combines several artifacts, such as videos from a primary school mathematics classroom, audio recordings of interviews with the teacher, lesson plan, mathematical tasks, students' responses, class verbal interactions and theoretical texts, to represent an inquiry-based mathematics teaching practice. The study took place in the context of a pre-service training course entitled "Mathematical Communication", which is located in the final year of an undergraduate course that qualifies students to enter a professional master's degree program for prospective primary school teachers. In this study, prospective teachers $(\mathrm{N}=15)$ participated, most of them female, aged between 20 and 23. Considering the intended objective, the study applied a qualitative methodology, and the data were obtained from the following sources: (i) students' answers to questions posed through the multimedia case: and (ii) written reflections (both were conducted in groups of $2 / 3$ students). The results show that the multimedia case contributed to the growth of students' knowledge about inquiry-based mathematics teaching, the conceptualization of communication that supports it, and about the teacher's actions and communication styles.
\end{abstract}

Keywords: Multimedia cases, Mathematics, Communication, Teachers' knowledge, Prospective School teachers.

\section{INTRODUCTIONN}

Teacher training seeks to provide future professionals with rich and meaningful learning experiences. One of these important experiences is the observation and analysis of teaching practices, whether in a real classroom environment or in one that does not take place on site. The need to allow prospective teachers to have access to good mathematics teaching practices has led some authors to advocate the use of video of mathematics classrooms as a complement to direct observation (Muñiz-Rodríguez et al., 2018; Kang \& Van Es, 2019). The use of this type of resource allows prospective teachers to view and review classes, to focus on some episodes or on some actors, favouring a close combination between theory and practice (Oliveira, Canavarro, \& Menezes, 2021; Kang \& Van Es, 2019; Star \& Strickland, 2008; Van Es \& Sherin, 2008). Within the scope of the P3M project - Professional Practices of Mathematics Teachers, Canavarro, Oliveira and Menezes $(2013,2021)$ developed multimedia cases of lessons of inquiry-based mathematics teaching to be used in teacher training sessions. These cases combine different digital artifacts, such as videos from mathematics classes, audio recordings of interviews with teachers, lesson plans, mathematical tasks, student's resolutions, class dialogs and theoretical texts, to represent an inquiry-based mathematics teaching.

One of these four cases developed, called "Cubes with stickers", was used within a "Mathematical communication" course (taking up 10 of the 30 hours allocated to the course), in a Teacher Training Undergraduate degree course (lasting 3 years), which entitles students to enrol in a professional master's degree course required for teaching, from kindergarten up to 6th year of schooling. The use of this multimedia case was planned to develop the didactic knowledge of prospective teachers, with a particular focus on knowledge about communication in the teaching and learning of Mathematics.

Thus, the study aims to understand the impact of a multimedia case of inquiry-based mathematics teaching, on the didactic knowledge of prospective teachers with focus on the knowledge of instructional communication. The study intends, in addition, to verify if the prospective teachers recognize the value of the multimedia case for their development. 


\section{MULTIMEDIA CASES AND TEACHER TRAINING}

The use of mathematics classroom cases as a resource for teacher training has some tradition, occurring when direct observation of classes is not possible or as a complement to this observation (Muñiz-Rodríguez et al., 2018; Kang \& Van Es, 2019; Star \& Strickland, 2008; Van Es \& Sherin, 2008). The use of these cases started to be written and then recorded on Video. In the P3M project, Oliveira, Canavarro and Menezes $(2013,2021)$ developed multimedia cases that combine several digital artifacts, identified in figure 1, to represent an inquiry-based mathematics teaching practice:

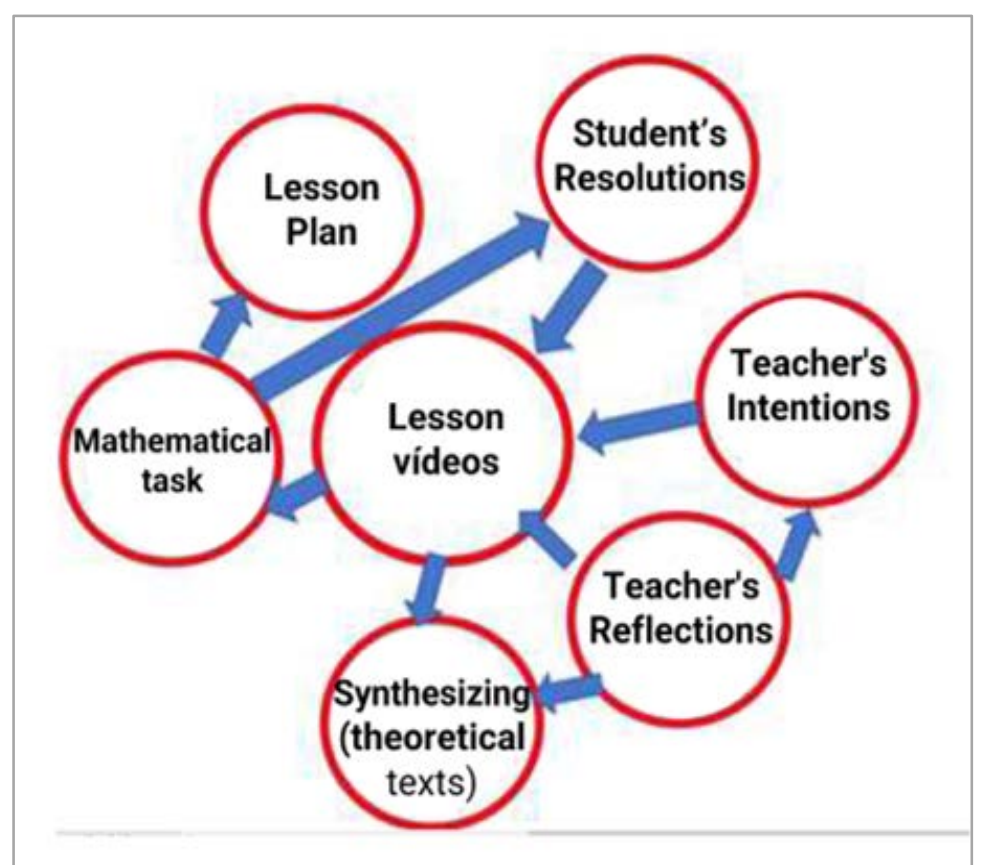

Figure 1: Structure of multimedia cases (adapted from Oliveira, Canavarro and Menezes, 2014).

Inquiry-based mathematics teaching is a very demanding practice for teachers, especially in initial training. This type of lesson is based on an intense activity on the part of students, which is originated from rich mathematical tasks involving mathematical concepts the teacher wants the students to learn.

A lesson in an inquiry-based approach is usually structured in three or four phases. Stein et al. (2008) consider the "launch phase", the "explore phase", and the "discuss and summarize phase". In the P3M project, we consider four phases: "launching the task for students", "Supporting student's autonomous work on the task", "Orchestrating the discussion of the task's resolutions; and "Systematizing mathematical learning" (Menezes, Oliveira, \& Canavarrro, 2015; Oliveira, Canavarro, \& Menezes, 2021).

The four multimedia cases built in the P3M Project were based on the observation and analysis of mathematics lessons from different levels of education (recorded on video, with two cameras, one fixed and the other one mobile), preceded and followed by interviews with teachers. The construction of the cases, which take the name of the mathematical tasks used in classes, was also supported by the existing knowledge about this type of teaching practices in Mathematics, namely with respect to the teacher's intentions and action in each of the phases of the lesson (Oliveira, Canavarro, \& Menezes, 2021). In figure 2 , we present the task "Cubes with stickers" used in a primary school class (grade 4). 


\section{Cubes with Stickers}

Joana is building a game with cubes and stickers. She connects the cubes through one of its faces and forms a queue of cubes. Then she glues a sticker in each of the cube's faces. The figure shows the construction that Joana did with 2 cubes. In that construction she used 10 stickers.

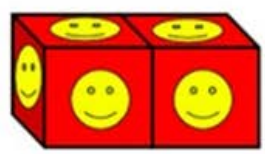

1. Find out how many stickers Joana used in a construction with:

1.1 Three cubes;

1.2 Four cubes;

1.3Ten cubes;

1.4 Fifty-two cubes.

2. Can you find out what is the rule that allows you to know how many stickers Joana used in a construction with any given number of cubes? Explain how you thinking

Figure 2: The task "Cubes with stickers" (Oliveira, Canavarro \& Menezes, 2014).

In figure 3 we present the interface of the multimedia case "Cubes with stickers". In the horizontal menu, the user finds the following sections: (i) Introduction to the multimedia case; (ii) The mathematical task; (iii) The class; (iv) Reflection after class; and (v) Practice. In the vertical menu, the user finds the four phases of the class and, in each of them, we have: (i) the teacher's planning; (ii) the development of the lesson (with videos, transcripts of dialogues and students' (re)solutions of the task); and (iii) Synthesizing (text of a theoretical nature). The theoretical text systematizes fundamental aspects related to the teacher's knowledge for each phase, namely those linked to instructional communication:

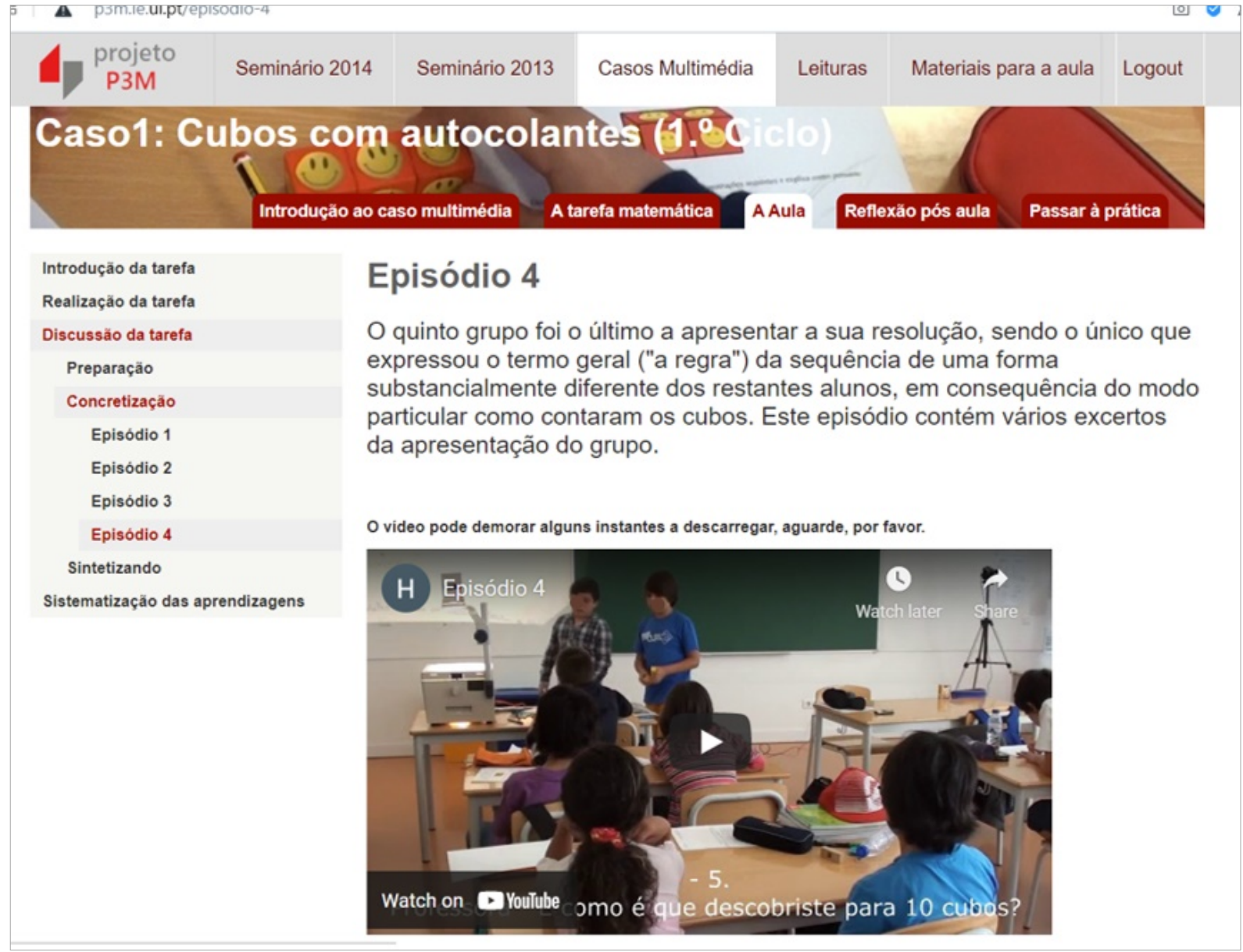

Figure 3: Multimedia case "Cubes with stickers" (Oliveira, Canavarro \& Menezes, 2013, 2014). 
Each multimedia case offers to the user a tour of exploration, with questions and tasks about it, to be solved and discussed. However, it is possible to follow other itineraries, as happened in this study in which it was intended to develop the didactic knowledge of future primary school teachers, paying particular attention to the communication that takes place in an inquiry-based mathematics teaching class.

\section{METHODOLOGY}

Due to the objectives of the study and the nature of the data, we opted for a qualitative methodology. In the study, 15 prospective teachers participated, most of them female, aged between 20 and 23 .

A multimedia case, called "Cubes with stickers", as part of a "Mathematical communication" course (lasting 10 hours, divided into 5 sessions each one lasting for 2 hours), in a Teacher Training Undergraduate Degree Course (lasting 3 years), which entitles students to enrol in a professional master's degree required for teaching, from kindergarten up to 6th year of schooling.

The data collection resulted from: (i) students' answers to questions posed in the multimedia case, and (ii) written reflections (both were carried out in groups of $2 / 3$ students).

Data analysis is based on content analysis, focusing on: (i) Impact of the multimedia case on didactic knowledge related to instructional communication; and (ii) Recognition of the instructive value of the multimedia case.

\section{RESULTS}

\subsection{Analysing the math class through the multimedia case}

The prospective teachers identify, in phase 1 , introducing the mathematical task, the teacher's purposes: to present, to the students, the task and to identify some aspects that may represent difficulties for them. In this respect, Group 7 highlighting the role of focusing and inquiry questions to support the introduction of the task:

Firstly, when introducing the task, the teacher starts the lesson with the presentation of the task, discussing several points it involves. The teacher starts by asking questions that aim to develop students' understanding and mathematical knowledge, through preparing questions (in which the teacher focuses the students' attention on one aspect she chooses) and inquiry questions (the teacher invites students to express their understanding, with the purpose of understanding the way students organize their thinking). (G 7)

Analysing teacher's actions in phase 2 - Supporting student's autonomous work -, prospective teachers emphasize the idea of communicating to understand students, not for validating answers, and also the use of several types of questions. Prospective teachers also point out the importance of students making clear records of their line of reasoning, to facilitate the collective discussion of task resolutions. The next phase of the lesson:

In this episode, we found that the teacher approached a group of students to understand their line of reasoning. In addition, she asked them to make clear records for use in the collective discussion. We verified that the teacher, at no time, mentions if the answer is correct or wrong, she just questions the students, to understand, using inquiry questions and focusing. (G5)

Then, in the collective discussion phase, prospective teachers underline the teacher's invitation for students to present and argue in favour of their ideas, emphasizing that they can agree or disagree, as long as they explain and justify. Prospective teachers also identify the discussion pattern of interaction at this stage of the lesson:

For the collective discussion, the teacher chooses three different (re)solutions, from among different groups of students, questioning all students regarding the similarities and differences of these resolutions. Then, the teacher leads students to draw their own conclusions. In this task, the teacher challenges students to reflect on the results, without presenting her opinion. (...) During the discussion, the teacher gave several students the opportunity to explain / justify their ideas in relation to the resolutions and allowed all other students to agree / disagree with the idea that was being presented. In this way, students share, with each other, the knowledge acquired in this task. The class follows the interaction pattern of discussion. (G 2) 
Prospective teachers consider this type of lesson of inquiry-based mathematics teaching as an adequate way for students to share knowledge, which will be systematized by the teacher, after a task or a set of tasks that involve the same mathematical content

\subsection{Prospective teachers' view of the multimedia case}

The prospective teachers were invited to reflect on the usefulness of the multimedia case for the development of their didactic knowledge, in particular, with regard to communication in the teaching and learning of Mathematics. The recognition of the importance of this multimedia resource was unanimous: "With the multimedia case of the P3M project, which was of great value to us, we were able to deepen the theme and we have access to more examples to understand the importance of good communication in mathematics classroom" (G3); "The present work, with the multimedia case, allowed us to become familiar with different communication practices in the classroom context, namely how the teacher acts and the importance of his actions." (G1).

The participants highlight some aspects related to the knowledge of communication in the Mathematics class, pointing out the concept of communication as a social interaction, which the teaching and learning of Mathematics rests upon:

The analysis of the multimedia case allowed us to study and better understand the theme of communication practices in a mathematics classroom. (...) We reflect on the practices we intend to foster as prospective teachers, who must meet the demands of communication as social interaction, through an inquiry-based mathematics teaching approach (...) opting for the communication styles appropriate to these practices, which, in our view, should be the styles of reflective communication and following a pattern of discussion. (G1)

The prospective teachers recognize that multimedia case has placed them with a challenging practice, which generates patterns of interaction that are different from the usual ones. This class is based on the discussion, in which the validation of ideas is not exclusive to the teacher, but the group altogether is accountable for them.

Throughout the lesson stages, with the task "Cubes with stickers," we saw that teachers followed, above all, the pattern of discussion and also the pattern of focusing. In exploratory classes, like the one we analyzed, the teacher makes use of the discussion pattern because she tries to provoke a collective validation, making the students interact with each other and validate their ideas, based on their resolutions. Thus, they present their resolution strategy, justify it and (...) finally take part in a debate of ideas that will be crucial for the learning of each student. (G3)

In order to develop mathematical knowledge, the teacher must interact through various communicative dynamics, bringing the student closer to the teacher and the other colleagues. An example of this is the collective discussions that are relevant not only in learning how to debate ideas but also in solving problems and learning mathematics. (G2)

Some prospective teachers underline, in the multimedia case, the possibility of seeing different types of questions that teachers use to boost communication, especially the challenging questions that lead students to think, to discover and to discuss. The multimedia case also seems to have contributed to build the idea of learning mathematics with meaning:

The questions have specific didactic purposes in the teacher discourse. (...) It is important that a teacher promotes discussion, launches challenges, questions and, above all, allows students to think and explain what their line of reasoning. It is necessary for the teacher to give them opportunities to find out things by themselves and draw their own conclusions. It is in this way that learning becomes more significant, as it happened in this multimedia case.

In general, prospective teachers show that they appreciated the use of the multimedia case, being able to highlight an important set of didactic knowledge that are related to the teaching and learning of Mathematics in a challenging class for students.

\section{CONCLUSIONS}

The study aims to understand the impact of a multimedia case on the didactic knowledge of prospective teachers and also to verify if they recognize the value of the multimedia case for their development.

The work done with the multimedia case "Cubes with stickers", especially the analysis of videos, transcriptions of dialogues and students' resolutions, were important for the development of the didactic 
knowledge of the prospective teachers regarding communication in the teaching and learning of Mathematics. This result is in line with the meta-analysis carried out by Oliveira, Canavarro and Menezes (2021),

Participants identify the teacher's communication style, the types of questions asked by the teacher and the intended objectives. They also identify other communicative actions developed by the teacher during class time, in order to make the students' learning meaningful. It should also be noted that participants signal the teacher's actions to get students to present and discuss their ideas, avoiding prior validation of responses. Prospective teachers identified patterns of interaction that the class was displaying.

Lastly, prospective teachers recognize that the multimedia case was important for the development of their didactic knowledge related to communication in the teaching and learning of Mathematics.

\section{ACKNOWLEDGEMENTS}

This work is funded by National Funds through the FCT - Foundation for Science and Technology, I.P., within the scope of the project Refa UIDB/05507/2020. Furthermore, we would like to thank the Centre for Studies in Education and Innovation (CI\&DEI) and the Polytechnic of Viseu for their support.

\section{REFERENCES}

[1] A. P. Canavarro, H. Oliveira, \& L. Menezes, "Práticas de ensino exploratório da Matemática: Ações e intenções de uma professora" In Práticas de ensino exploratório da Matemática: Ações e intenções de uma professora (J. P. Ponte, ed.), 217-233, Lisboa: Instituto de Educação, 2014.

[2] E. Van Es, \& M, Sherin, "Mathematics teachers' learning to notice in the context of a video club". Teaching and Teacher Education, vol. 24, no.2, pp. 244-276, 2008.

[3] H. Kang, \& E. Van Es, "Articulating design principles for productive use of video in preservice education". Journal of Teacher Education, vol.70, no.3, pp. 237-250, 2019.

[4] H. Oliveira, A. P. Canavarro, \& L. Menezes, "Cubos com autocolantes (1. ${ }^{\circ}$ ciclo $)$ - caso multimédia" in P3M Project Website (Accessible in http://p3m.ie.ul.pt/caso1-cubos-com-autocolantes-1-ciclo), 2012.

[5] H. Oliveira, A. P. Canavarro, \& L. Menezes, "Desenvolver novas perspetivas sobre o ensino da Matemática através da análise da prática: os casos multimédia na formação de professores" in Formação de Professores e Tecnologias Digitais (A. Richit \& H. Oliveira, eds.), 117-142, São Paulo: Editora Livraria da Física, 2021.

[6] J. R. Star, \& S. K. Strickland. "Learning to observe: Using video to improve preservice mathematics teachers' ability to notice", Journal of mathematics teacher education, vol. 11, no.2, pp.107-125, 2008.

[7] L. Menezes, H. Oliveira, \& A. P. Canavarro, "Inquiry-based mathematics teaching: The case of Célia" in Educational paths to Mathematics (U. Gellert, J. Gimenez Rodriguez, C. Hahn, S. Kafoussi, eds.), 305-321, Cham: Springer, 2015.

[8] L. Muñiz-Rodríguez, P. Alonso, L. J. Rodríguez-Muñiz, K. Coninck, R. Vanderlinde, \& M. Valcke, "Exploring the effectiveness of video-vignettes to develop mathematics student teachers' feedback competence", Eurasia Journal of Mathematics Science and Technology Education, vol. 14, no. 1, pp. 1-17, 2018.

[9] R. A Stein, Engle, M. S. Smith \& E. K. Hughes, "Orchestrating Productive Mathematical Discussions: Five Practices for Helping Teachers Move Beyond Show and Tell", Thinking and Learning, vol. 10, no. 4, pp. 313-340, 2008. 